\title{
Effects of KH-204 on the expression of heat shock protein 70 and germ cell apoptosis in infertility rat models
}

\author{
Woong Jin Bae ${ }^{1}$, U Syn $\mathrm{Ha}^{2}$, Kang Sup Kim², Su Jin Kim², Hyuk Jin Cho², Sung Hoo Hong², Ji Youl Lee²,
} Zhiping Wang ${ }^{3}$, Sung Yeoun Hwang ${ }^{4}$ and Sae Woong Kim²*

\begin{abstract}
Background: Idiopathic infertility is a significant number of causes of male infertility. Empirical treatments are used for idiopathic male infertility, and antioxidant supplementation is a kind of management of oxidative stress related infertility. We investigated the antioxidant effects of the modified Ojayeonjonghwan (KH-204) in a rat model of cryptorchidism.

Method: Male rats were divided into four groups ( $n=8$ in each): a normal control group, a cryptorchidism-induced control group and two cryptorchidism-induced groups treated p.o. with either 200 or 400 mg/kg, KH-204 for 4 weeks. The testes and epididymides from rats in all groups were removed, weighed and subjected to histological examination and semen analysis after surgery. Oxidative stress was assessed by measuring 8-hydroxy-20-deoxyguanosine (8-OHdG), superoxide dismutase (SOD) and heat shock protein (HSP) levels. Apoptosis was determined using a terminal deoxyribonucleotidyl transferase-mediated dUTP-digoxigenin nick end-labeling assay.

Results: Treatment with the multi-herbal medicine $\mathrm{KH}$-204 (1) increased the mean weight of the cryptorchid testes; (2) restored sperm counts, motility and germinal cell layer thickness; (3) decreased levels of 8-OHdG and increased levels of SOD; and (4) decreased HSP70 levels and apoptosis.

Conclusions: $\mathrm{KH}-204$ reduces the oxidative stress in an experimental rat model of cryptorchidism, and it may alleviate HSP expression and germ cell apoptosis.
\end{abstract}

Keywords: Infertility, male, Phytotherapy, Spermatozoa, Antioxidants

\section{Background}

About $15 \%$ sexually active couples suffered from infertility and the prevalence rate is increasing [1]. In $40 \%$ of these couples, the male partner has been either the single or a contributing cause of infertility [2]. About $42.6 \%$ of male infertility is caused by known etiologies such as varicocele, undescended testes, or hypogonadism [3]; however the etiology and pathogenesis are still not fully understood and are referred to as idiopathic infertility in a significant number of cases of male infertility [4]. Currently, empirical treatments are used for idiopathic male infertility, and many pharmacological agents have been

\footnotetext{
*Correspondence: ksw1227@catholic.ac.kr

2Department of Urology, College of Medicine, The Catholic University of Korea, 222 Banpo-daero, Seocho-gu, Seoul 137-701, Republic of Korea
} Full list of author information is available at the end of the article used with varying degrees of efficacy. Antioxidant supplement is a kind of management of oxidative stress related infertility, because oxidative stress is one of the main issues associated with male infertility [5]. Several studies have reported that reactive oxygen species (ROS) cause infertility by decreasing sperm motility, breaking the sperm membrane and directly damaging sperm DNA $[6,7]$.

Several nutritional supplements and herbal medicines have demonstrated antioxidant or free radical scavenging activities $[8,9]$. They exhibit beneficial effects on sperm function. For example, Safarinejad et al. showed that nutritional supplement such as selenium, N-acetylcysteine, omega-3 and co-enzyme Q10 improved semen parameters [10-12].

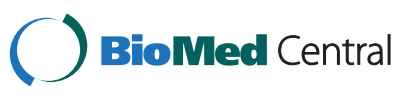

(C) 2014 Bae et al.; licensee BioMed Central Ltd. This is an Open Access article distributed under the terms of the Creative Commons Attribution License (http://creativecommons.org/licenses/by/4.0), which permits unrestricted use, distribution, and reproduction in any medium, provided the original work is properly credited. The Creative Commons Public Domain Dedication waiver (http://creativecommons.org/publicdomain/zero/1.0/) applies to the data made available in this article, unless otherwise stated. 
Recently, administration of herbs for the treatment of infertility has become popular, despite a lack of scientific studies to assess their effectiveness and safety [13]. Schizandra chinensis Baillon, Rubus coreanus Miquel, Cuscuta chinensis Lam, and Lycium chinense Mill are herbs popularly used in Korean oriental medicine, and these herbal formulation, Ojayeonjonghwan is used to treat male infertility. In addition, each of them has displayed antioxidant activities in a variety of diseases [14-17]. Recently, Kim et al. [18] performed a preliminary study with modified Ojayeonjonghwan investigating the toxicity and influence of five herbs on normal reproductive organs. Their results suggested a safe and positive influence on sperm quality after oral administration of herbal compounds. However, the effects and mechanisms underlying the action of the herbal formulation in an infertility model have not been clearly elucidated. It was hypothesized that the positive influence on sperm quality after treatment would be attributed to the antioxidant effect of each component. In the present study we investigated the antioxidant effects of the herbal formulation $\mathrm{KH}-204$ in an experimental rat model of cryptorchidism.

\section{Methods}

\section{Preparation of the herbal formula (KH-204)}

The major ingredients in the herbal formula were obtained from five plants; 32\% Cornus officinalis Sieb. Et Zucc, 4\% Schizandra chinensis Baillon, 16\% Rubus coreanus Miquel, 16\% Cuscuta chinensis Lam, and 32\% Lycium chinense Mill. This new herbal formula originated from Korean traditional medicine, and has been shown to be effective for reproductive or erectile function [19]. The content of each plant and the manufacture method are reported by previous studies $[18,19]$. Each of the components was placed in $5 \mathrm{~L}$ of distilled water and refluxed at $100-120^{\circ} \mathrm{C}$ for $6 \mathrm{~h}$. The extract was filtered, and the water from the filtrate was removed by a rotary evaporator and a spray dryer (SD-1000, EYELA, Japan). Korea Bio Medical Science Institute (KBMSI) Co. Ltd., a venture company that develops oriental herbal medicines, developed this product as a health supplement.

\section{Animal groups and treatment protocol}

Thirty-two 8-week-old male Sprague-Dawley rats were treated under a protocol approved by the Institutional Animal Care and Use Committee in School of Medicine, The Catholic University of Korea (Approval Nubmer: CUMC-2013-0030-01) and handled according to NIH guidelines. Rats were divided equally into four groups ( $\mathrm{n}=8$ in each): Control, the normal control group; Crypto-control, unilateral cryptorchidism-induced controls; Crypto-200, unilateral cryptorchidism-induced rats administered $200 \mathrm{mg} / \mathrm{kg}$ of $\mathrm{KH}-204$; Crypto-400, unilateral cryptorchidism-induced rats administered $400 \mathrm{mg} / \mathrm{kg}$ of $\mathrm{KH}-204$. In each group, once-daily oral administration of either distilled water (control, Crypto-control) or KH-204 (Crypto-200, Crypto-400) was continued for 4 weeks. KH204 was dissolved in distilled water and administered orally through an $8 \mathrm{~F}$ red Rob-Nel catheter once a day. The dosage of $\mathrm{KH}-204$ and duration of treatment were selected based on results from a previous experiment [18].

Unilateral cryptorchidism in rats was surgically induced as previously described [20]. Animals were anesthetized with pentobarbital, and a small incision was made in the abdomen of each rat. The left gubernaculum of each rat was cut to displace the left testis into the abdomen, and the left inguinal canal was closed by suturing to prevent testis descent. The right testis, which did not undergo surgery, was used as the paired control. The animals in all groups were killed 4 weeks after surgery, and blood samples were collected. The abdominal control scrotal testes and epididymides were removed and weighed. One-third of the testicular tissue from each individual testis was fixed and embedded for histologic examination, and the remaining tissues were used for measurement of oxidative stress, heat shock protein (HSP) expression and apoptosis.

\section{Cauda epididymal sperm count and motility}

The cauda epididymides were minced in $5 \mathrm{~mL}$ normal saline containing $0.5 \%$ bovine serum albumin at $37^{\circ} \mathrm{C}$ and then filtered. Sperm suspensions were placed on glass slides that had been prewarmed to $37^{\circ} \mathrm{C}$. The percentage of motile spermatozoa was determined by counting more than 200 spermatozoa in randomly selected fields under a light microscope. Sperm counts were expressed as the number of motile spermatozoa per gram cauda epididymis tissue. An expert investigator blinded to the experimental groups evaluated the samples.

\section{Histologic evaluation- measurement of spermatogenic cell density}

The testicular tissues obtained were fixed in $10 \%$ neutral formalin, embedded in paraffin, stained with haematoxylin-eosin and examined under a light microscope at $\times 400$ magnification. Ten representative sites in seminiferous tubules that were almost round were selected randomly and spermatogenic cell density was determined by measuring the thickness of the germinal cell layer and the diameter of the seminiferous tubules.

\section{Measurement of oxidative stress}

Oxidative stress in testes tissues was assessed quantitatively by measuring the 8-hydroxy-2-deoxyguanosine (8-OHdG) and superoxide dismutase (SOD). By use of the DNeasy Blood \& Tissue kit (Qiagen, Valencia, CA, USA), total DNA was extracted from the testis. The 8-OHdG levels 
were measured with a DNA oxidation kit (Highly Sensitive 8-OHdG Check ELISA; Japan Institute for the Control of Aging, Fukuroi, Japan). After the final color was developed with the addition of 3, 3', 5, 5' -tetramethylbenzidine, absorbance was measured at $450 \mathrm{~nm}$. Tissue sample concentration was calculated from a standard curve and was corrected for DNA concentration. SOD activity (CuZnSOD and Mn SOD) in tissue was measured using a SOD Assay Kit-WST (Dojindo), monitoring the decrease in the rate of superoxide-mediated reduction of nitroblue tetrazolium at $450 \mathrm{~nm}$ using a spectrophotometer.

\section{HSP 70 determination by western blot analysis}

The testis tissues were ground to a fine powder in a liquid nitrogen-cooled mortar and pestle. The testis total protein was extracted using a cell lysis buffer $(20 \mathrm{mM}$ Tris- $\mathrm{HCl}$ pH7.5, $150 \mathrm{mM} \mathrm{NaCl}, 1 \mathrm{mM}$ Na2EDTA, $1 \mathrm{mM}$ EGTA, 1\% Triton, $2.5 \mathrm{mM}$ sodium pyrophosphate, $1 \mathrm{mM} \beta$-glycerophosphate, $1 \mathrm{mM} \mathrm{Na3VO} 4,1 \mu \mathrm{g} / \mathrm{ml}$ leupeptin and $1 \mathrm{mM}$ phenylmethylsulfonly fluoride). Protein extracts were quantified with the BCA Protein Aassay Reagent (Thermo Scientific, Rockford, IL, USA). Quantitative proteins $(20 \mu \mathrm{g})$ were boiled in loading buffer $(62.6 \mathrm{mM}$ Tris- $\mathrm{HCl} \mathrm{pH} 6.8,2 \%$ sodium dodecyl sulfate [SDS], $0.01 \%$ bromophenol blue, $10 \%$ glycerol, and $100 \mathrm{mM}$ DTT). Proteins were loaded per lane and resolved by $10 \%$ (HSP-70) SDS-polyacrylamide gel electrophoresis (SDS-PAGE). Proteins were transferred onto Hybond-ECL nitrocellulose membrane (Amersham Biosciences, Germany) and equal protein loading was verified by Ponceau-S staining (Sigma-Aldrich). The membranes were blocked by treatment 5\% non-fat milk in Tris-buffered saline containing $0.1 \%$ Tween 20 and membranes were probed with anti-HSP-70 antibody (1:1000; Abcam) and anti$\beta$-Actin antibody (1:10000; SIGMA) for internal control as previously described. Immunoreactivation were emitted by using horseradish peroxydase conjugated secondary antibody (Santa Cruz Biotechnology, CA, USA) Densitometric analysis of band intensity was detected by Luminescent Image Analysis System (LAS-3000; FUJIFILM, Japan) and measured using Multi Gauge 3.0 software (FUJI Photo Film, Japan).

\section{Assessment of apoptosis- TUNEL assay}

Testicular tissue sections were rinsed with phosphatebuffered saline (PBS) after blocking with 0.1\% Triton X-100 for $5 \mathrm{~min}$. Terminal deoxyribonucleotidyl transferasemediated dUTP-digoxigenin nick end-labelling (TUNEL, ApopTag In Situ Apoptosis Detection Kits; Millipore, MA, USA) detection solution was dropped on to the sections and they were incubated at $37^{\circ} \mathrm{C}$ in the dark for $1 \mathrm{~h}$. Nuclear staining with DAPI was carried out for $5 \mathrm{~min}$ after rinsing with $\mathrm{PBS}$, and the sections were mounted with $50 \%$ glycerol after rinsing with PBS. For the control sections, the TUNEL solution was replaced with PBS. The sections were observed under a fluorescence microscope and photographed, and cells from ten randomly selected visual fields were counted to determine the apoptotic index [21].

\section{Statistical analysis}

All data are presented as the mean \pm standard deviation. Data were analysed using SPSS for (version 12.0; SPSS Inc., Chicago, IL, USA). Data were evaluated using analysis of variance (ANOVA), with group comparisons made by Scheffe's test. A p-value less than 0.05 was considered statistically significant.

\section{Results}

\section{Testis weight}

The mean body weights and testicular weights are listed in Table 1. There were no significant differences in body weights and right (contralateral) testicular weights among the groups. The average left testicular weight from the Crypto-control group was significantly lower than that of the Control group ( $\mathrm{p}<0.05)$, but was not different from that of the Crypto-200 group. However, the mean weight of the left testes from the Crypto- 400 group was significantly greater than that of the Cryptocontrol group $(\mathrm{p}<0.05)$.

\section{Sperm counts and motility}

Mean sperm counts and the percentage of motile spermatozoa in the left epididymis are given in Figure 1. The sperm counts and motility from the Crypto-control group were significantly decreased compared with the Control group $(\mathrm{p}<0.05)$, and these same parameters were significantly increased compared with the Cryptocontrol group after oral administration of $400 \mathrm{mg}$ of the new herbal formula $\mathrm{KH}-204(\mathrm{p}<0.05)$ (Figure 1).

\section{Spermatogenic cell density}

In the Control group, several layers of spermatocytes formed the germinal cell layer (Figure 2A). However, in the Crypto-control group, the spermatocyte count was decreased, and necrosis was evident (Figure 2B). The

Table 1 The mean body weights and testicular weights after treatment

\begin{tabular}{llll}
\hline & Body weight & $\begin{array}{l}\text { Right testicular } \\
\text { weight }\end{array}$ & $\begin{array}{l}\text { Left testicular } \\
\text { weight }\end{array}$ \\
\hline Control & $512.66 \pm 11.52$ & $1.71 \pm 0.11$ & $1.72 \pm 0.31$ \\
Crypto-control & $550.12 \pm 20.12$ & $1.84 \pm 0.09$ & $0.47 \pm 0.06^{*}$ \\
Crypto-200 & $533.33 \pm 10.19$ & $1.67 \pm 0.20$ & $0.57 \pm 0.01$ \\
Crypto-400 & $566.67 \pm 13.58$ & $1.70 \pm 0.09$ & $0.83 \pm 0.15^{* *}$ \\
\hline
\end{tabular}

Data show the mean \pm s.d., Analysis of variance test, ${ }^{*}$ Significant statistical difference $(p<0.05)$ compared with the Control group. ${ }^{* *}$ Significant statistical difference $(p<0.05)$ compared with the Crypto-control group. 

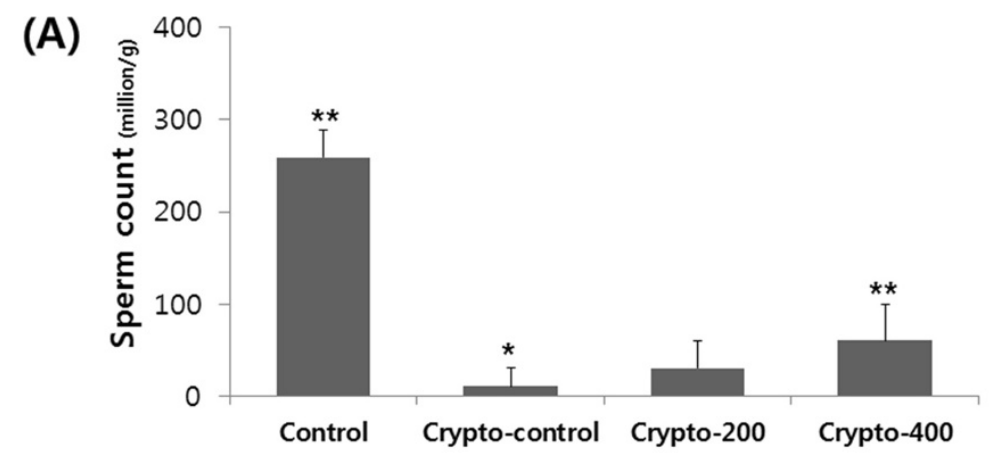

(B)

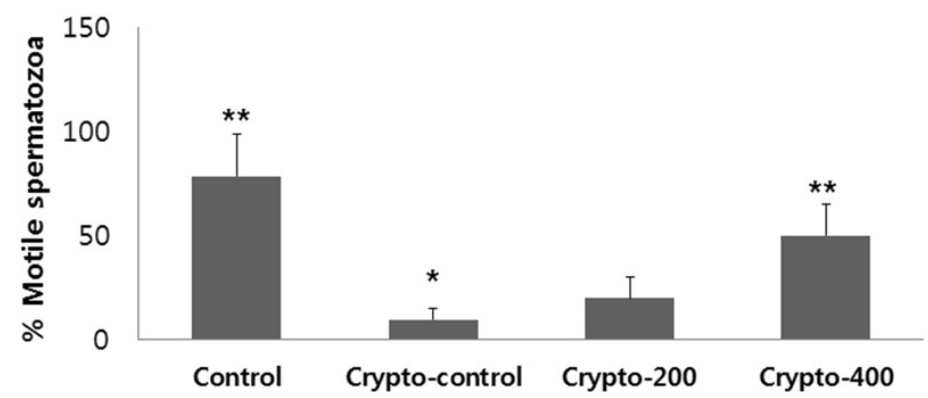

Figure 1 Effect of the new herbal formula on sperm count and motility. Sperm count (A) and activity (B) after 4-week oral administration of the new herbal formula. ${ }^{*}, p<0.05$ as compared with the Control group. ${ }^{* *}, p<0.05$ as compared with the Crypto-control group. By analysis of variance test.

spermatocyte count and germinal cell layer thickness were higher in Crypto-200 and Crypto-400 rats than in the Crypto-control (Figure $2 \mathrm{C}$ and $\mathrm{D}$ ). The thickness of the germinal cell layer and the diameter of the seminiferous tubules in the Crypto- 400 group was significantly increased compared with that of Crypto-control, and was similar to that of Control rats (Table 2).

\section{Measurement of oxidative stress}

Mean 8-OHdG and SOD expression in the left testes are shown in Figure 3. A dose-dependent decrease in 8-OHdG and an increase in SOD were observed in the treatment groups. Oxidative stress was found to be significantly higher in the Crypto-control group compared with the Control group $(\mathrm{p}<0.05)$, but significantly lower in Crypto-200 and Cryto-400 rats compared with Crypto-control rats $(\mathrm{p}<0.05)$.

\section{Expression of HSP 70}

Significant increases in HSP70 were exhibited in the Crypto-control group, but KH-204 administration significantly decreased HSP70 levels in the testes of experimental rats (Figure 4). HSP70 levels in the Crypto-200 and Crypto-400 group were significantly decreased compared with those of the Crypto-control and were similar to those of Control rats.

\section{Assessment of apoptosis}

Cells undergoing apoptosis form cellular apoptotic cells, which were observed as dark red in color in the TUNEL assay (Figure 5). Compared with the Crypto-control, the apoptotic cell counts in the left testes were significantly lower in the Control, Crypto-200 and Crypto-400 groups $(\mathrm{p}<0.05$, respectively).

\section{Discussion}

The main findings of our study were as follows: (1) treatment with the multi-herbal medicine $\mathrm{KH}-204$ increased the mean weight of the cryptorchid testis; (2) treatment with $\mathrm{KH}-204$ restored sperm counts, motility and germinal cell layer thickness; (3) levels of 8-OHdG decreased and levels of SOD increased following treatment with $\mathrm{KH}-204$; and (4) HSP70 levels and apoptotic cells in the treatment group were significantly decreased as compared with those of the Crypto-control group and were similar to those of the Control group.

We observed that the mean volume of the left testes in the cryptorchidism-induced group without treatment was significantly lower than that of the pared control right testes at 4 weeks as well as that of the left testes in the normal control group. In addition, the spermatogenic cell density of the left testes was significantly lower in cryptorchidism-induced controls than in the normal control group. Heat stress induces the generation of 

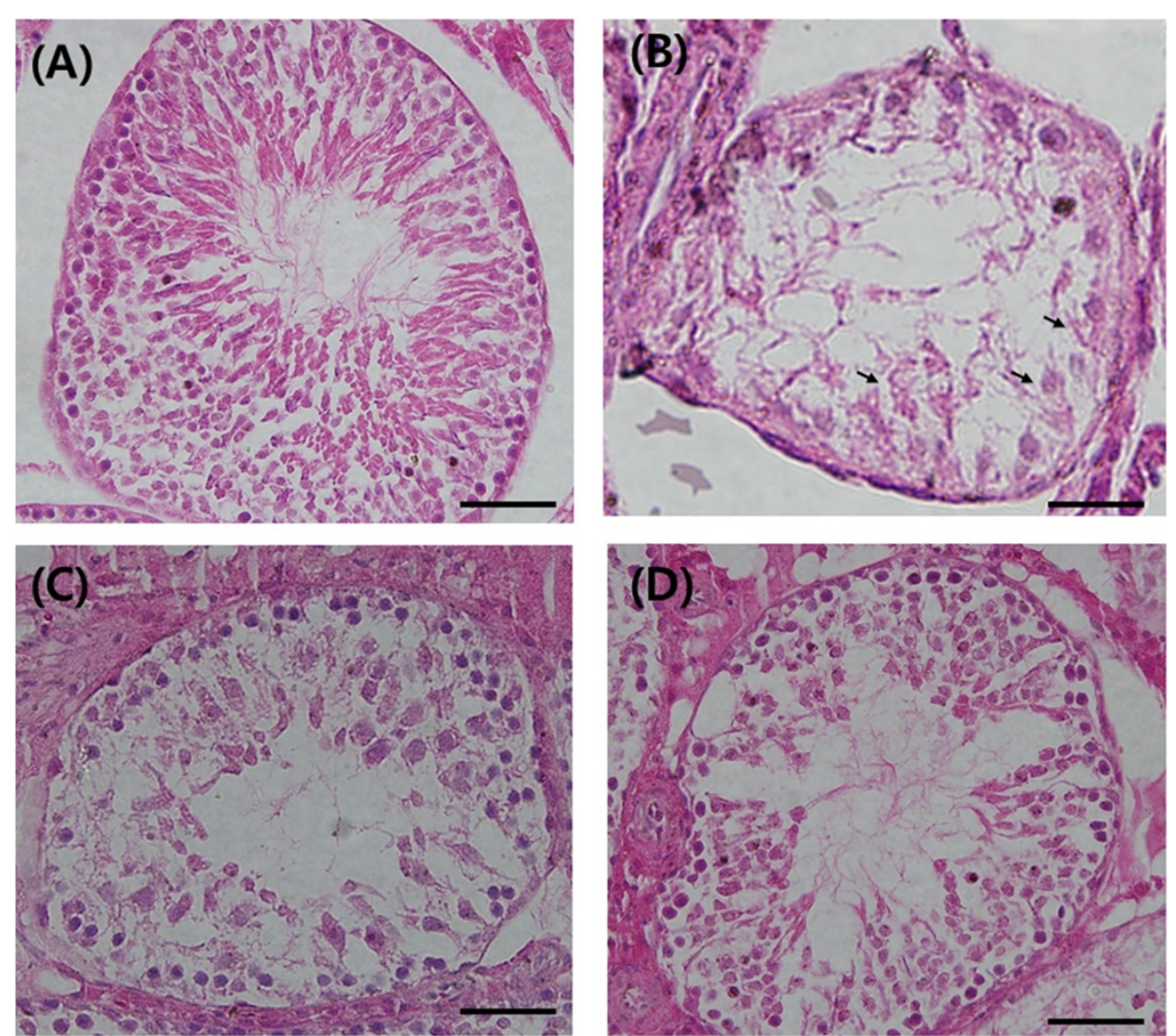

Figure 2 Histopathological findings of left testis (haematoxylin and eosin stain) in (A) the normal control group ( $n=8$, Conrtol), (B) the cryptorchidism-induced controls ( $\mathrm{n}=8$, Crypto-control), (C) cryptorchidism-induced rats treated with $200 \mathrm{mg} / \mathrm{kg}(\mathrm{n}=8, \mathrm{Crypto}-200)$ and (D) cryptorchidism-induced rats treated with $\mathbf{4 0 0} \mathbf{~ m g / k g ~ ( ~} \mathbf{n = 8}$ Crypto-400). Compared with Conrtol, some necrosis (arrow) and a narrow germinal cell layer is observed Crypto-control. In the treated groups (C, D), the germinal cell layer is thicker than in Crypto-control. Scale bars shown in each figure represent $100 \mu \mathrm{m}$.

ROS in the testes [22,23] and a reduction of endogenous antioxidant enzymes such as SOD and catalase [24]. SOD plays an important role in the male testes. A recent study demontrated that the presence of high levels of $\mathrm{CuZn}$ SOD and $\mathrm{Zn}$ render spermatogonia resistant to ROS, and consequently protected from oxidative stress [25]. Superoxide anion, hydroxyl radical, nitric oxide and hydrogen peroxide are among the ROS generated $[26,27]$. These ROS are transitory molecules with a

Table 2 The thickness of the germinal cell layer and the diameter of the seminiferous tubules in each group (um)

\begin{tabular}{lll}
\hline & $\begin{array}{l}\text { Germinal cell layer } \\
\text { thickness }\end{array}$ & $\begin{array}{l}\text { Diameter of seminiferous } \\
\text { tubules }\end{array}$ \\
\hline Control & $80.13 \pm 5.16$ & $302.25 \pm 3.21$ \\
Crypto-control & $32.38 \pm 8.13^{*}$ & $242.48 \pm 2.50^{*}$ \\
Crypto-200 & $45.13 \pm 1.19$ & $255.71 \pm 1.46$ \\
Crypto-400 & $69.23 \pm 2.11^{* *}$ & $281.54 \pm 9.82^{* *}$ \\
\hline
\end{tabular}

Data show the mean \pm s.d., Analysis of variance test, ${ }^{*}$ Significant statistical difference $(p<0.05)$ compared with the Control group. ${ }^{* * *}$ Significant statistical difference $(p<0.05)$ compared with the Crypto-control group. high degree of chemical reactivity that could affect spermatogonia for life, thus reducing sperm production and male fertility [28]. Excessive oxidative stress contributes to a deterioration of sperm quality by breaking the balance between ROS and antioxidants in men with infertility. Increased ROS production leads to the peroxidation of the sperm acrosomal membrane and decreased acrosin activity; therefore, the fertilization process cannot be completed $[29,30]$. Furthermore, ROS directly damages the sperm DNA by directly attacking the DNA molecule or by initiating apoptosis within the sperm, which induces the caspase-mediated enzymatic degradation of DNA [31]. Therefore, antioxidant administration may help to restore the imbalance of an excessive level of ROS and improve sperm quality. Several oral supplements and herbs have been proposed to improve male factor infertility [32]. These supplements have been shown to instigate improvement in sperm parameters, and the antioxidant properties of these supplements are thought to counteract ROS found in higher concentrations among some men with oligoasthenospermia [10,33-36]. 


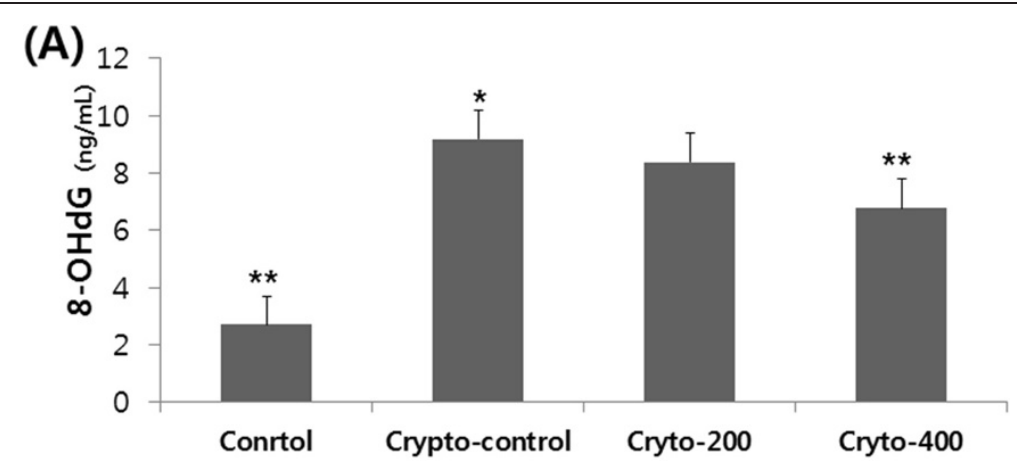

(B)

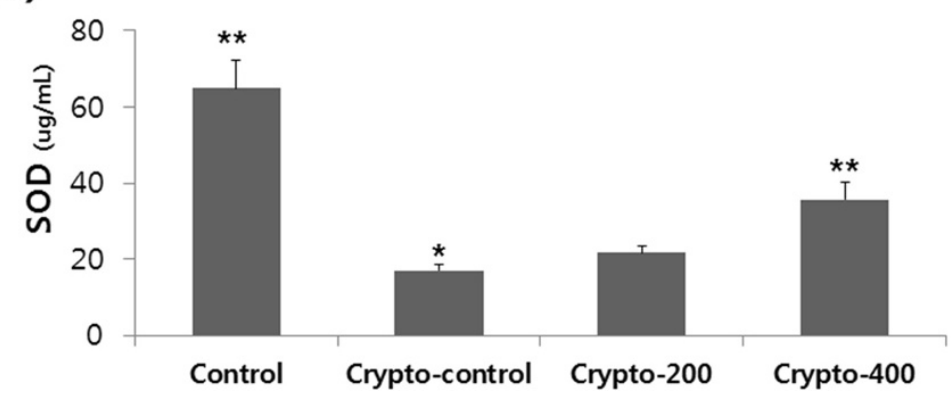

Figure 3 Comparison of the expression levels of $\mathbf{8 - O H d G}(\mathbf{A})$ and SOD (B). ${ }^{*}, p<0.05$ as compared with the Control group. ${ }^{* *}, p<0.05$ as compared with Crypto-control. By analysis of variance test.

(A)

\section{HSP-70}

$\beta$-actin

(B)

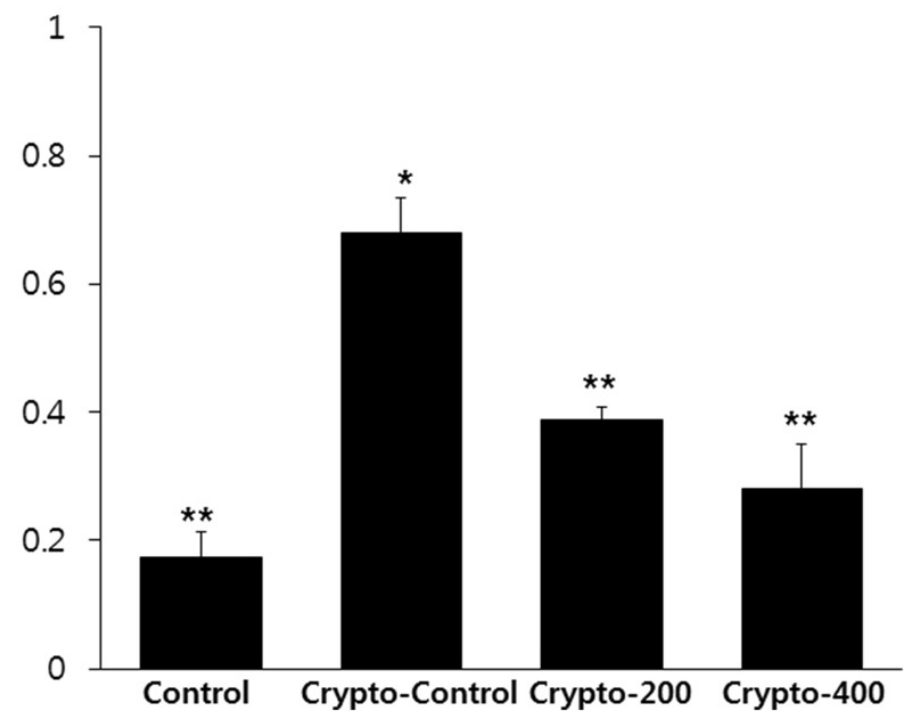

Figure 4 Comparison of the expression levels of HSP70 (A) and densitometric analysis relative to beta-actin of HSP70 (B). ${ }^{*}, p<0.05$ as compared with the Control group. ${ }^{* *}, p<0.05$ as compared with the Crypto-control group. By analysis of variance test. 


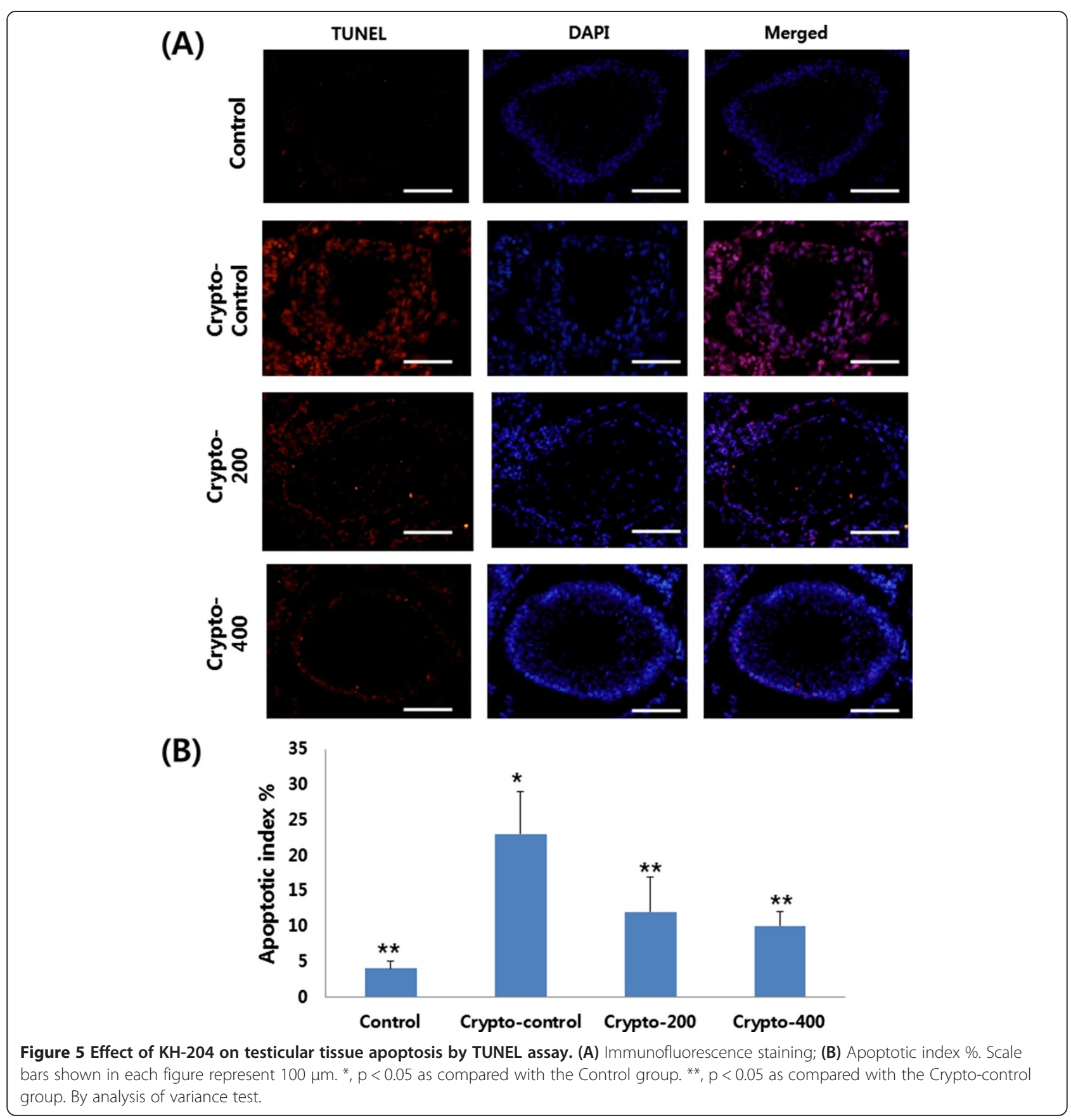

A number of stimuli induce HSP70, including energy depletion, hypoxia, acidosis, ischemia-reperfusion and ROS [37]. However, the association of HSP70 with semen quality is not clearly understood in experimental animals and humans, and results obtained are conflicting. Rockett et al. [38] demonstrated that both the levels of heat-inducible HSP70 and apoptosis were increased in mice spermatocytes exposed to heat. Their results indicated that under same conditions, spermatogenesis was disrupted. In our study, an increase in the expression of HSP70 was observed in the cryptorchidism-induced controls (Crypto-control) with an increase in free radical exposure. Under conditions of oxidative stress, testicular germ cells can produce high levels of stress response proteins, including HSPs, which protect against free radical insult [39]. Erata et al. [40] evaluated the expression of HSP70 in male infertility and found a positive correlation with DNA damage detected in sperm. It seems to confirm that increased HSP70 expression would assist in blocking aggregation and refolding of damaged proteins as 
a general protective response. In general, DNA bases and phosphodiester backbones are particularly susceptible to oxidative stress. Many reports suggests that high levels of reactive oxygen species cause the DNA fragmentation commonly observed in the spermatozoa of infertile men [41-43]. Previously also improvements in redox status were associated with reduced HSP70 mRNA levels in rats. In the present study, the decrease in the protein expression of HSP70 was observed in treatment groups.

We found that $\mathrm{KH}-204$ treatment can decrease oxdiative stress and apoptosis in cryptorchidism-induced rats. It is likely that the therapeutic effects of $\mathrm{KH}-204$ are at least in part attributable to suppression of ROS production. Our results may provide relevant evidence for the use of the new herbal formula for treating male infertility. A previous study demonstrated that the toxicity of $\mathrm{KH}-204$ might be less than that of the several herbs such as Rubus coreanus and Cuscuta chinensis when used alone; hence, the safety of this new formulation has been proven to some degree [18].

One potential limitation of our study was that the model used is far from an accurate model of infertility secondary to oxidative stress. It is well known that oxidative stress, which is caused by the excessive generation of ROS, can also induce DNA damage in spermatozoa $[44,45]$. Heat stress is implicated in the induction of oxidative stress within the testis $[24,46]$. Secondly, through this study, we identified anti-oxidant and anti-apoptotic effects of a new herbal formulation in cryptorchidisminduced rats, however, while we observed improvement, we did not see complete restoration of sperm counts, motility or germinal cell layer thickness. In addition, there is no time-course data although we observed antioxidant effect in a dose-dependent manner. Future work should investigate the detailed mechanism of $\mathrm{KH}-204$ with its anti-oxidant effect in subfertility animal model.

\section{Conclusion}

The present study demonstrated that $\mathrm{KH}-204$ reduces the oxidative stress in an experimental rat model of cryptorchidism, and it may alleviate HSP expression and germ cell apoptosis.

\section{Competing interests}

The authors have no actual or potential competing interest associated with this work.

\section{Authors' contributions}

WJB drafted the manuscript, and participated in every part of the experiments. USH participated in the design of the study and helped in the experiments and drafting of the manuscript. KSK participated in the design, biochemical assays and statistical analysis of the study. SJK, HJC, and SHH participated in the experiments, coordinated among the authors and helped to draft the manuscript. JYL, ZW and SYH participated in the design of the study and drafting of the manuscript. SWK participated in the design of the study and experiments of the study. All of the authors read and approved the final manuscript.

\section{Acknowledgements}

This study was supported by Research Fund of Seoul St. Mary's Hospital, The Catholic University of Korea. This work was supported by a grant from the Next-Generation BioGreen 21 Program (No. PJ009546), Rural Development Administration, Republic of Korea.

\section{Author details}

${ }^{1}$ Catholic Integrative Medicine Research Institute, College of Medicine, The Catholic University of Korea, Seoul, Korea. ${ }^{2}$ Department of Urology, College of Medicine, The Catholic University of Korea, 222 Banpo-daero, Seocho-gu, Seoul 137-701, Republic of Korea. ${ }^{3}$ Department of Urology, Second Hospital of Lanzhou University, Lanzhou, China. ${ }^{4}$ Korea Bio Medical Science Institute, Seoul, Korea.

Received: 5 June 2014 Accepted: 24 September 2014 Published: 1 October 2014

\section{References}

1. Irvine DS: Epidemiology and aetiology of male infertility. Hum Reprod 1998, 13(Suppl 1):33-44.

2. Smith JF, Eisenberg ML, Millstein SG, Nachtigall RD, Shindel AW, Wing H, Cedars M, Pasch L, Katz PP: The use of complementary and alternative fertility treatment in couples seeking fertility care: data from a prospective cohort in the United States. Fertil Steril 2010, 93(7):2169-2174.

3. Jungwirth A, Giwercman A, Tournaye H, Diemer T, Kopa Z, Dohle G, Krausz C: European Association of Urology guidelines on Male Infertility: the 2012 update. Eur Urol 2012, 62(2):324-332.

4. Deng Y, Zhang W, Su D, Yang Y, Ma Y, Zhang H, Zhang S: Some single nucleotide polymorphisms of MSY2 gene might contribute to susceptibility to spermatogenic impairment in idiopathic infertile men. Urology 2008, 71(5):878-882.

5. Mahfouz R, Sharma R, Sharma D, Sabanegh E, Agarwal A: Diagnostic value of the total antioxidant capacity (TAC) in human seminal plasma. Fertil Steril 2009, 91(3):805-811.

6. Tremellen $\mathrm{K}$ : Oxidative stress and male infertility-a clinical perspective. Hum Reprod Update 2008, 14(3):243-258.

7. Irvine DS, Twigg JP, Gordon EL, Fulton N, Milne PA, Aitken RJ: DNA integrity in human spermatozoa: relationships with semen quality. J Andro/ 2000, 21(1):33-44.

8. Liu F, Ng TB: Antioxidative and free radical scavenging activities of selected medicinal herbs. Life Sci 2000, 66(8):725-735.

9. $\mathrm{Ng}$ TB, Liu F, Wang ZT: Antioxidative activity of natural products from plants. Life Sci 2000, 66(8):709-723.

10. Safarinejad MR: Efficacy of coenzyme Q10 on semen parameters, sperm function and reproductive hormones in infertile men. J Urol 2009, 182(1):237-248.

11. Safarinejad MR: Effect of omega-3 polyunsaturated fatty acid supplementation on semen profile and enzymatic anti-oxidant capacity of seminal plasma in infertile men with idiopathic oligoasthenoteratospermia: a double-blind, placebo-controlled, randomised study. Andrologia 2011, 43(1):38-47.

12. Safarinejad MR, Safarinejad S: Efficacy of selenium and/or N-acetyl-cysteine for improving semen parameters in infertile men: a double-blind, placebo controlled, randomized study. J Urol 2009, 181(2):741-751.

13. Clark NA, Will MA, Moravek MB, Xu X, Fisseha S: Physician and patient use of and attitudes toward complementary and alternative medicine in the treatment of infertility. Int J Gynaecol Obstet 2013, 122(3):253-257.

14. Cheng N, Ren N, Gao H, Lei X, Zheng J, Cao W: Antioxidant and hepatoprotective effects of Schisandra chinensis pollen extract on CCl4-induced acute liver damage in mice. Food Chem Toxicol 2013, 55:234-240.

15. Bhandary B, Lee HY, Back HI, Park SH, Kim MG, Kwon JW, Song JY, Lee HK, Kim HR, Chae SW, Chae HJ: Immature rubus coreanus shows a free radical-scavenging effect and inhibits cholesterol synthesis and secretion in liver cells. Indian J Pharm Sci 2012, 74(3):211-216.

16. Yen FL, Wu TH, Lin LT, Lin CC: Hepatoprotective and antioxidant effects of Cuscuta chinensis against acetaminophen-induced hepatotoxicity in rats. J Ethnopharmacol 2007, 111(1):123-128.

17. Lin CC, Chuang SC, Lin JM, Yang JJ: Evaluation of the antiinflammatory hepatoprotective and antioxidant activities of Lycium chinense from Taiwan. Phytomedicine 1997, 4(3):213-220. 
18. Kim SJ, Kim MR, Hwang SY, Bae WJ, Kim S, Hong SH, Lee JY, Hwang TK, Wang Z, Kim SW: Preliminary report on the safety of a new herbal formula and its effect on sperm quality. World J Mens Health 2013, 31(3):254-261.

19. Sohn DW, Kim HY, Kim SD, Lee EJ, Kim HS, Kim JK, Hwang SY, Cho YH, Kim SW: Elevation of intracavernous pressure and NO-cGMP activity by a new herbal formula in penile tissues of spontaneous hypertensive male rats. J Ethnopharmacol 2008, 120(2):176-180

20. Shikone T, Billig H, Hsueh AJ: Experimentally induced cryptorchidism increases apoptosis in rat testis. Biol Reprod 1994, 51(5):865-872.

21. Kang HW, Kim JM, Cha MY, Jung HC, Song IS, Kim JS: Deguelin, an Akt inhibitor, down-regulates NF-kappaB signaling and induces apoptosis in colon cancer cells and inhibits tumor growth in mice. Dig Dis Sci 2012, 57(11):2873-2882.

22. DeFoor WR, Kuan CY, Pinkerton M, Sheldon CA, Lewis AG: Modulation of germ cell apoptosis with a nitric oxide synthase inhibitor in a murine model of congenital cryptorchidism. J Urol 2004, 172(4 Pt 2):1731-1735.

23. Vigueras-Villaseñor RM, Molina-Ortiz D, Reyes-Torres G, del Angel DS, Moreno-Mendoza NA, Cruz ME, Cuevas-Alpuche O, Rojas-Castañeda JC: Effect of allopurinol on damage caused by free radicals to cryptorchid testes. Acta Histochem 2009, 111(2):127-137.

24. Ahotupa M, Huhtaniemi I: Impaired detoxification of reactive oxygen and consequent oxidative stress in experimentally cryptorchid rat testis. Biol Reprod 1992, 46(6):1114-1118.

25. Celino FT, Yamaguchi S, Miura C, Ohta T, Tozawa Y, Iwai T, Miura T: Tolerance of spermatogonia to oxidative stress is due to high levels of Zn and Cu/Zn superoxide dismutase. PLoS One 2011, 6(2):e16938.

26. Kumagai A, Kodama H, Kumagai J, Fukuda J, Kawamura K, Tanikawa H, Sato $\mathrm{N}$, Tanaka T: Xanthine oxidase inhibitors suppress testicular germ cell apoptosis induced by experimental cryptorchidism. Mol Hum Reprod 2002, 8(2):118-123.

27. Ishii T, Matsuki S, luchi Y, Okada F, Toyosaki S, Tomita Y, Ikeda Y, Fujii J: Accelerated impairment of spermatogenic cells in SOD1-knockout mice under heat stress. Free Radic Res 2005, 39(7):697-705.

28. Ghosh D, Das UB, Misro M: Protective role of alpha-tocopherol-succinate (provitamin-E) in cyclophosphamide induced testicular gametogenic and steroidogenic disorders: a correlative approach to oxidative stress. Free Radic Res 2002, 36(11):1209-1218.

29. Zalata AA, Ahmed AH, Allamaneni SS, Comhaire FH, Agarwal A: Relationship between acrosin activity of human spermatozoa and oxidative stress. Asian J Androl 2004, 6(4):313-318.

30. Jedrzejczak P, Fraczek M, Szumała-Kakol A, Taszarek-Hauke G, Pawelczyk L, Kurpisz M: Consequences of semen inflammation and lipid peroxidation on fertilization capacity of spermatozoa in in vitro conditions. Int J Androl 2005, 28(5):275-283.

31. Villegas J, Schulz M, Soto L, Iglesias T, Miska W, Sánchez R: Influence of reactive oxygen species produced by activated leukocytes at the level of apoptosis in mature human spermatozoa. Fertil Steril 2005, 83(3):808-810.

32. Clark NA, Will M, Moravek MB, Fisseha S: A systematic review of the evidence for complementary and alternative medicine in infertility. Int J Gynaecol Obstet 2013, 122(3):202-206.

33. Agarwal A, Sekhon LH: The role of antioxidant therapy in the treatment of male infertility. Hum Fertil (Camb) 2010, 13(4):217-225.

34. Greco E, lacobelli M, Rienzi L, Ubaldi F, Ferrero S, Tesarik J: Reduction of the incidence of sperm DNA fragmentation by oral antioxidant treatment. J Androl 2005, 26(3):349-353.

35. Omu AE, Al-Azemi MK, Kehinde EO, Anim JT, Oriowo MA, Mathew TC Indications of the mechanisms involved in improved sperm parameters by zinc therapy. Med Princ Pract 2008, 17(2):108-116.

36. Wong WY, Merkus HM, Thomas CM, Menkveld R, Zielhuis GA, Steegers Theunissen RP: Effects of folic acid and zinc sulfate on male factor subfertility: a double-blind, randomized, placebo-controlled trial. Fertil Steril 2002, 77(3):491-498.

37. Kiang JG, Tsokos GC: Heat shock protein 70 kDa: molecular biology, biochemistry, and physiology. Pharmacol Ther 1998, 80(2):183-201.

38. Rockett JC, Mapp FL, Garges JB, Luft JC, Mori C, Dix DJ: Effects of hyperthermia on spermatogenesis, apoptosis, gene expression, and fertility in adult male mice. Biol Reprod 2001, 65(1):229-239.

39. Ogi S, Tanji N, Iseda T, Yokoyama M: Expression of heat shock proteins in developing and degenerating rat testes. Arch Androl 1999, 43(3):163-171.
40. Erata GO, Koçak Toker N, Durlanik O, Kadioğlu A, Aktan G, Aykaç Toker G: The role of heat shock protein 70 ( $\mathrm{Hsp} 70)$ in male infertility: is it a line of defense against sperm DNA fragmentation? Fertil Steril 2008, 90(2):322-327.

41. O'Brien J, Zini A: Sperm DNA integrity and male infertility. Urology 2005, 65(1):16-22.

42. Wang X, Sharma RK, Sikka SC, Thomas AJ Jr, Falcone T, Agarwal A: Oxidative stress is associated with increased apoptosis leading to spermatozoa DNA damage in patients with male factor infertility. Fertil Steril 2003, 80(3):531-535.

43. Moustafa MH, Sharma RK, Thornton J, Mascha E, Abdel-Hafez MA, Thomas AJ Jr, Agarwal A: Relationship between ROS production, apoptosis and DNA denaturation in spermatozoa from patients examined for infertility. Hum Reprod 2004, 19(1):129-138.

44. Aitken RJ, Gordon E, Harkiss D, Twigg JP, Milne P, Jennings Z, Irvine DS: Relative impact of oxidative stress on the functional competence and genomic integrity of human spermatozoa. Biol Reprod 1998, 59(5):1037-1046.

45. Aitken RJ, Baker MA: Oxidative stress, sperm survival and fertility control. Mol Cell Endocrinol 2006, 250(1-2):66-69.

46. Li YC, Hu XQ, Xiao L, Hu ZY, Guo J, Zhang KY, Song XX, Liu YX: An oligonucleotide microarray study on gene expression profile in mouse testis of experimental cryptorchidism. Front Biosci 2006, 11:2465-2482.

doi:10.1186/1472-6882-14-367

Cite this article as: Bae et al:: Effects of $\mathrm{KH}-204$ on the expression of heat shock protein 70 and germ cell apoptosis in infertility rat models. BMC Complementary and Alternative Medicine 2014 14:367.

\section{Submit your next manuscript to BioMed Central and take full advantage of:}

- Convenient online submission

- Thorough peer review

- No space constraints or color figure charges

- Immediate publication on acceptance

- Inclusion in PubMed, CAS, Scopus and Google Scholar

- Research which is freely available for redistribution 